\title{
Factors associated with the adoption of a smoking ban in Quebec households
}

\author{
É. Ouedraogo, MD (1); F. Turcotte, MD (2); M. J. Ashley, MD, DPH (3); J. M. Brewster, PhD (4); R. Ferrence, PhD (5)
}

\begin{abstract}
The home represents an important source of exposure to environmental tobacco smoke for non-smokers, including children, who live with smokers. Our goal is to identify the sociodemographic factors associated with the adoption of smoking bans in "smoker households" in Quebec. Selected associations are compared with three other Canadian provinces (Ontario, British Columbia and Nova Scotia). This is a cross-sectional study involving 2648 respondents. Logistic regression analysis is employed. Few smoker households in Quebec $(21 \%)$ have a ban on smoking; the presence of a non-smoker is strongly linked to the existence of such a ban; the presence of a child under the age of 6 is less strongly associated with the adoption of a ban in Quebec than in the other provinces, and the presence of an adolescent shows no association whatsoever. In addition to the child health benefits of household smoking bans, greater emphasis should be placed on the impact that such bans can have on children's future smoking behaviour. One option from a health promotion standpoint might be to organize a campaign aimed at non-smokers who live with smokers, in order to urge them to be less tolerant of environmental tobacco smoke.
\end{abstract}

Key words: environmental tobacco smoke, smoke-free home, sociodemographic factors, Quebec households

\section{Introduction}

The harmful health effects of environmental tobacco smoke (ETS) on non-smokers are now well-established. ${ }^{1-3}$ In Canada, measures to limit exposure to ETS have been introduced in workplaces and in a variety of public places as well. ${ }^{i}$ Numerous studies have shown that such measures not only improve the health and comfort level of non-smokers, but also reduce smokers' consumption of tobacco products. ${ }^{4}$
However, the home remains an important source of exposure to ETS, particularly for pre-school children. The favourable response to smoking restrictions in public places and places of work and the diminishing social acceptability of smoking suggest that such measures could be extended to the private sphere. In Ontario, the proportion of non-smokers who favour a complete ban on smoking in the presence of small children increased by $15.4 \%$ between 1992 and 1996, while opposition to such measures on the part of smokers decreased by $8.6 \%$ during the same period. ${ }^{5}$
There is only limited data on smoking bans in Canadian households. A 1995 study carried out by Health Canada with households that included children aged 12 or younger found that $19 \%$ of such households had a complete ban on smoking, $44 \%$ had a partial ban, and $37 \%$ had no restrictions. ${ }^{6-7}$ However, the response rate for this study was only $50 \%$.

Despite a remarkable reduction in the prevalence of smoking, Quebec remains above the Canadian average in terms of ETS exposure. According to the most recent Canadian Tobacco Use Monitoring Survey (CTUMS) conducted in 2006, the prevalence of Quebecois children aged 0 to 17 who are exposed to ETS in the home is $21.6 \%$, compared to $11.2 \%$ in Canada as a whole. ${ }^{8}$

As far as we know, there are no population data describing the effect of sociodemographic factors on the adoption of household smoking bans in Quebec. The objective of this study is to identify the sociodemographic characteristics of households and respondents most strongly associated with the existence of a smoking ban in Quebec households that include at least one smoker, and to establish comparisons with three other Canadian provinces (Ontario, British Columbia and Nova Scotia).

i Measures to limit exposure to ETS are in place even in the "private" environment of the car: under a new Ontario law that came into effect on January 21, 2009, charges can be laid against any person found smoking in a vehicle that is also carrying a child under the age of 16.

Author References

1 Département Médecine Sociale et Préventive, Faculté de médecine, Université Laval, QC 2 Département Médecine Sociale et Préventive, Faculté de médecine, Université Laval, QC 3 Dalla Lana School of Public Health, University of Toronto, ON

4 Ontario Tobacco Research Unit, Dalla Lana School of Public Health, University of Toronto, ON

5 Ontario Tobacco Research Unit, Centre for Addiction and Mental Health University of Toronto, ON

Correspondence: Éva Ouedraogo, MD, Département Médecine Sociale et Préventive, Faculté de médecine, Université Laval, Tel.: 418-666-7000 ext. 236, Fax: 418-666-2776 ;

Email: eva.ouedraogo@ssss.gouv.qc.ca 


\section{Methodology}

This is a cross-sectional population study. The data are derived from the National Survey on Environmental Tobacco Smoke in the Home and were collected between June 2001 and January 2002 by the Institute for Social Research at York University, under the direction of the Ontario Tobacco Research Unit (OTRU).

The sampling and questionnaires have already been described. ${ }^{9}$ In brief, the initial sample comprised 14600 households; respondents were asked to complete an initial questionnaire to determine the smoking status of their households, as well as the presence of children under the age of 18. In order to gather information on smoking bans, a second sample of "smoker households" was selected. In this sample, households that included at least one adult smoker and a child were over-represented since the goal was to obtain a sample size that was sufficiently large for statistical analysis; on the basis of these criteria, 5000 households from every province in Canada were selected. From these households, 2648 smoker households with and without children were selected in four provinces (Quebec, Ontario, British Columbia and Nova Scotia). While the original survey extended to all parts of Canada, Ontario and British Columbia were selected in order to compare Quebec with provinces that show better smoking ban prevalence rates in the literature, and Nova Scotia was selected because it is comparable to Quebec, with the exception of its cultural context.

A smoker household is defined as a household in which at least one person aged 18 or over smokes cigarettes, cigars, cigarillos or a pipe on a daily or occasional basis. Although information was collected on every smoker in any given household, few people under the age of 18 live away from their parents and are in a position to establish their own household smoking rules. ${ }^{9}$

Participants were selected on the basis of computer-generated telephone numbers. Information was collected using a questionnaire that was administered with the aid of computer-assisted telephone interviewing (CATI) technology. To ensure an optimal response rate, a maximum of 14 calls were made to any number for which contact was not established on the first call; 10 of these calls were made in the evening or on weekends.

The dependent variable is the household smoking ban. A smoke-free household is a home in which all occupants refrain from smoking inside at all times. The behaviour of visitors and guests with respect to household smoking bans was not taken into account. Smoking bans were measured on the basis of people's response to the following question: "Do you smoke cigarettes, cigars, cigarillos or a pipe at home every day, from time to time, or not at all?" In cases where the household had more than one smoker, the question was put to the respondent for every other smoker. This information provided a means of defining a variable with two response levels: (1) a complete household smoking ban; or (2) a partial ban or no ban.

The results are expressed as weighted prevalence ratios. A weighting system was introduced in order to take into account the unequal probability of households being selected on the basis of their composition, since smoker households with children were more likely to be selected than those with no smokers or children. We also needed to take into account the unequal distribution of households by province of origin. A weighting coefficient was assigned to each type of household.

Initially, univariate unconditional logistic regression was used to identify the variables most strongly associated with the adoption of a household smoking ban. Then, a multivariate analysis was performed. Provincial variations in the effect of a sociodemographic characteristic on the adoption of a smoking ban were evaluated using a logistic regression model that was stratified for the province and adjusted for the other characteristics. To avoid the problem of colinearity, variables contributing the same information were not included in the model at the same time. The weighted prevalence ratios thus obtained were used to estimate the association between each variable and the presence of a household smoking ban with a confidence interval of $95 \%$.

These statistical analyses were performed using SAS software.

\section{Results}

\section{Sociodemographic characteristics and household smoking ban prevalence}

A total of 2648 respondents representing households with at least one adult smoker agreed to complete the questionnaire in the four provinces. The survey response rate was $62 \%$. Tables 1 and 2 present the characteristics of respondents and households respectively. The proportion of female respondents was slightly greater than that of male respondents; more than half of all respondents were in a couple relationship. Close to $50 \%$ had a highschool education or less. Sixty-three percent of respondents were cigarette and/ or pipe, cigar or cigarillo smokers; $80 \%$ of these smokers smoked every day. Slightly over one third of the households had at least one child; in $37 \%$ of cases that child was under the age of 6. In Quebec, 949 smoker households agreed to complete the questionnaire. The characteristics of the Quebec sample are comparable to those of the total sample. Given the large number of missing values for household income, the effect of this variable was not included in the analysis of associations.

The weighted prevalence of household smoking bans in Quebec is $21 \%$; this is significantly different from the rates observed in Ontario and British Columbia which were, respectively, 43.7\% ( $p<0.0001)$ and $52.1 \%$ ( $p<0.0001)$, but not statistically different from the rate observed in Nova Scotia $(32 \%)(p=0.64)$.

\section{Factors associated with the adoption of a household smoking ban in Quebec}

Table 3 presents the results of the univariate and multivariate analyses. Several respondent characteristic variables are significantly associated with the adoption of a household smoking ban in a univariate analysis, but this is no longer the case once other variables are taken into account. Thus, the age, gender and smoking status of respondents have no impact on the 
TABLE 1

Characteristics of respondents in the provinces of Quebec, Ontario, British Columbia and Nova Scotia

\begin{tabular}{|c|c|c|c|c|c|c|c|c|c|c|c|c|c|c|c|}
\hline \multirow[t]{2}{*}{ Variables } & \multicolumn{3}{|c|}{ Quebec } & \multicolumn{3}{|c|}{ Ontario } & \multicolumn{3}{|c|}{ British Columbia } & \multicolumn{3}{|c|}{ Nova Scotia } & \multicolumn{3}{|c|}{ Totala } \\
\hline & $n^{b}$ & $\% c$ & $\% W^{d}$ & $\mathbf{n}$ & $\%$ & $\% W$ & $\mathbf{n}$ & $\%$ & $\% W$ & n & $\%$ & $\% W$ & $\mathbf{n}$ & $\%$ & $\% W$ \\
\hline \multicolumn{16}{|l|}{ Age group (in years) } \\
\hline $18-24$ & 156 & 16.5 & 22.0 & 165 & 14.0 & 19.2 & 52 & 14.7 & 19.2 & 18 & 13.8 & 19.1 & 391 & 15.0 & 20.1 \\
\hline $25-64$ & 718 & 76.1 & 70.5 & 949 & 80.8 & 75.1 & 267 & 75.6 & 71.1 & 103 & 79.2 & 73.5 & 2037 & 78.3 & 72.9 \\
\hline$\geq 65$ & 69 & 7.3 & 7.5 & 61 & 5.2 & 5.7 & 34 & 9.6 & 9.6 & 9 & 6.9 & 7.4 & 173 & 6.6 & 7.0 \\
\hline Total & 943 & & & 1175 & & & 353 & & & 130 & & & 2601 & & \\
\hline \multicolumn{16}{|l|}{ Gender } \\
\hline Women & 549 & 57.8 & 56.0 & 669 & 55.5 & 52.8 & 194 & 53.7 & 49.2 & 66 & 50.0 & 42.9 & 1478 & 55.8 & 52.9 \\
\hline Men & 400 & 42.1 & 44.0 & 537 & 44.5 & 47.2 & 167 & 46.3 & 50.8 & 66 & 50.0 & 57.1 & 1170 & 44.2 & 47.1 \\
\hline Total & 949 & & & 1206 & & & 361 & & & 132 & & & 2648 & & \\
\hline \multicolumn{16}{|l|}{ Smoking status } \\
\hline Current smoker & 646 & 68.4 & 63.5 & 814 & 68.0 & 62.9 & 222 & 61.7 & 57.0 & 97 & 74.0 & 71.8 & 1779 & 67.5 & 62.6 \\
\hline Former smoker & 137 & 14.5 & 15.8 & 157 & 13.1 & 15.1 & 59 & 16.4 & 47.0 & 16 & 12.2 & 12.2 & 369 & 14.0 & 15.5 \\
\hline Non-smoker & 162 & 17.1 & 20.7 & 227 & 18.9 & 22.0 & 79 & 21.9 & 26.0 & 18 & 13.8 & 16.0 & 486 & 18.5 & 21.9 \\
\hline Total & 945 & & & 1198 & & & 360 & & & 131 & & & 2634 & & \\
\hline \multicolumn{16}{|l|}{ Marital status } \\
\hline $\begin{array}{l}\text { Living with } \\
\text { a spouse }\end{array}$ & 560 & 59.4 & 58.9 & 695 & 58.1 & 57.0 & 205 & 57.1 & 56.5 & 84 & 63.6 & 63.6 & 1544 & 58.7 & 57.8 \\
\hline $\begin{array}{l}\text { Single/separated/ } \\
\text { divorced }\end{array}$ & 383 & 40.7 & 41.1 & 502 & 41.9 & 43.0 & 154 & 42.9 & 43.5 & 48 & 36.4 & 36.4 & 1087 & 41.3 & 42.2 \\
\hline Total & 943 & & & 1197 & & & 359 & & & 132 & & & 2631 & & \\
\hline \multicolumn{16}{|l|}{ Education level } \\
\hline $\begin{array}{l}\text { Bachelor's degree } \\
\text { or higher }\end{array}$ & 132 & 14.0 & 13.3 & 218 & 18.4 & 18.6 & 70 & 19.5 & 20.5 & 15 & 11.6 & 14.5 & 435 & 16.6 & 17.0 \\
\hline Post secondary & 318 & 33.8 & 35.6 & 564 & 47.6 & 47.1 & 186 & 51.8 & 51.1 & 25 & 19.4 & 18.9 & 1093 & 32.4 & 33.1 \\
\hline $\begin{array}{l}\text { Secondary } \\
\text { or lower }\end{array}$ & 491 & 52.2 & 51.1 & 402 & 34.0 & 34.3 & 103 & 28.7 & 28.4 & 89 & 69.0 & 66.6 & 1085 & 51.0 & 49.9 \\
\hline Total & 941 & & & 1184 & & & 359 & & & 129 & & & 2613 & & \\
\hline \multicolumn{16}{|c|}{ Perception of ETS as } \\
\hline $\begin{array}{l}\text { An important } \\
\text { health problem }\end{array}$ & 566 & 59.9 & 59.8 & 844 & 70.4 & 70.0 & 257 & 71.4 & 71.4 & 96 & 73.3 & 74.2 & 1763 & 67.9 & 67.1 \\
\hline $\begin{array}{l}\text { A health problem } \\
\text { of little or } \\
\text { no importance }\end{array}$ & 380 & 40.1 & 40.2 & 354 & 29.6 & 30.0 & 103 & 28.6 & 28.6 & 35 & 27.7 & 25.8 & 872 & 33.1 & 32.9 \\
\hline Total & 946 & & & 1198 & & & 360 & & & 131 & & & 2635 & & \\
\hline \multicolumn{16}{|c|}{ ETS in the workplace } \\
\hline Complete ban & 370 & 70.9 & 70.3 & 472 & 78.3 & 78.9 & 143 & 90.5 & 89.6 & 31 & 68.9 & 66.0 & 1016 & 76.8 & 77.3 \\
\hline Partial ban & 131 & 29.1 & 29.7 & 131 & 21.7 & 21.1 & 15 & 9.5 & 10.4 & 14 & 31.1 & 34.0 & 291 & 23.2 & 22.7 \\
\hline Total & 501 & & & 603 & & & 158 & & & 45 & & & 1307 & & \\
\hline
\end{tabular}

a The total may differ from the sample size (2648) due to missing values.

b $n$ represents the size of the sample.

c \% represents unweighted proportions.

d \%W represents weighted proportions. A weighting coefficient was assigned to each type of household to take into account the unequal probability of a household being selected on the basis of its composition. 
TABLE 2

Characteristics of households in the provinces of Quebec, Ontario, British Columbia and Nova Scotia

\begin{tabular}{|c|c|c|c|c|c|c|c|c|c|c|c|c|c|c|c|}
\hline \multirow[t]{2}{*}{ Variables } & \multicolumn{3}{|c|}{ Quebec } & \multicolumn{3}{|c|}{ Ontario } & \multicolumn{3}{|c|}{ British Columbia } & \multicolumn{3}{|c|}{ Nova Scotia } & \multicolumn{3}{|c|}{ Total $^{a}$} \\
\hline & $\mathbf{n}^{\mathbf{b}}$ & $\%^{c}$ & $\% W^{d}$ & $\mathbf{n}$ & $\%$ & $\% W$ & $\mathbf{n}$ & $\%$ & $\% W$ & $\mathbf{n}$ & $\%$ & $\% W$ & $\mathbf{n}$ & $\%$ & $\% W$ \\
\hline \multicolumn{16}{|c|}{ Presence of $\geq 1$ adult non-smoker } \\
\hline Yes & 576 & 60.7 & 68.9 & 719 & 59.6 & 68.8 & 225 & 62.3 & 70.0 & 72 & 54.5 & 61.7 & 1592 & 60.1 & 68.7 \\
\hline No & 373 & 39.3 & 31.1 & 487 & 40.4 & 31.2 & 136 & 37.7 & 30.0 & 60 & 45.5 & 38.3 & 1056 & 39.9 & 31.3 \\
\hline Total & 949 & & & 1206 & & & 361 & & & 132 & & & 2648 & & \\
\hline \multicolumn{16}{|l|}{ Presence of a child } \\
\hline Yes & 449 & 47.3 & 35.5 & 621 & 51.5 & 39.8 & 171 & 47.4 & 35.2 & 64 & 48.5 & 37.7 & 1305 & 49.3 & 37.7 \\
\hline No & 500 & 52.7 & 64.5 & 585 & 48.5 & 60.2 & 190 & 52.6 & 64.8 & 68 & 51.5 & 62.3 & 1343 & 50.7 & 62.3 \\
\hline Total & 949 & & & 1206 & & & 361 & & & 132 & & & 2648 & & \\
\hline \multicolumn{16}{|l|}{ Age of the child } \\
\hline 5 or under & 155 & 34.6 & 33.3 & 236 & 38.5 & 38.1 & 69 & 41.1 & 41.0 & 20 & 31.7 & 32.3 & 480 & 37.2 & 36.8 \\
\hline $6-17$ & 293 & 65.4 & 66.7 & 377 & 61.5 & 61.9 & 99 & 58.9 & 59.0 & 43 & 68.3 & 67.7 & 812 & 62.8 & 63.2 \\
\hline Total & 448 & & & 613 & & & 168 & & & 63 & & & 1292 & & \\
\hline \multicolumn{16}{|l|}{ Family context } \\
\hline $\begin{array}{l}\text { Adult non-smoker } \\
\text { and child }\end{array}$ & 282 & 29.7 & 24.8 & 370 & 30.9 & 26.6 & 108 & 30.2 & 26.6 & 29 & 22.1 & 17.4 & 789 & 29.9 & 25.6 \\
\hline $\begin{array}{l}\text { Adult non-smoker, } \\
\text { no child }\end{array}$ & 293 & 30.9 & 44.1 & 342 & 28.5 & 42.0 & 114 & 31.8 & 43.0 & 42 & 32.1 & 44.3 & 791 & 30.0 & 42.9 \\
\hline $\begin{array}{l}\text { Adult smoker } \\
\text { and child }\end{array}$ & 166 & 17.5 & 10.7 & 243 & 20.3 & 12.8 & 60 & 16.8 & 9.7 & 34 & 25.9 & 17.0 & 503 & 19.1 & 11.8 \\
\hline $\begin{array}{l}\text { Adult smoker, } \\
\text { no child }\end{array}$ & 207 & 21.8 & 20.4 & 243 & 20.3 & 18.6 & 76 & 21.2 & 20.6 & 26 & 26.9 & 21.3 & 552 & 21.0 & 19.6 \\
\hline Total & 948 & & & 1198 & & & 358 & & & 131 & & & 2635 & & \\
\hline \multicolumn{16}{|l|}{ Family income } \\
\hline$>95,000$ & 63 & 8.6 & 10.5 & 144 & 15.7 & 19.8 & 30 & 11.1 & 12.3 & 10 & 9.7 & 11.8 & 247 & 12.2 & 15.2 \\
\hline $55,000-95,000$ & 158 & 21.3 & 22.8 & 256 & 28.0 & 27.7 & 79 & 29.4 & 31.4 & 16 & 15.5 & 16.8 & 509 & 25.1 & 26.2 \\
\hline$\leq 55,000$ & 519 & 70.1 & 66.7 & 516 & 56.3 & 52.5 & 160 & 59.5 & 56.3 & 77 & 74.8 & 71.4 & 1272 & 62.7 & 58.6 \\
\hline Total & 740 & & & 916 & & & 269 & & & 103 & & & 2028 & & \\
\hline
\end{tabular}

a The total may differ from the sample size (2648) due to missing values.

b $n$ represents the size of the sample.

c \% represents unweighted proportions.

d \%W represents weighted proportions. A weighting coefficient was assigned to each type of household to take into account the unequal probability of a household being selected on the basis of its composition.

adoption of a smoking ban, nor does the respondent's status as a single or attached person. The perception of ETS as a major health problem has an effect that falls within the range of statistical significance. The education level of respondents has an influence on the adoption of a smoking ban, with an adjusted prevalence ratio (PR) of 3.26 (95\% confidence interval [CI] 2.0 to 5.3$)$.

The impact of each household characteristic on the adoption of a household smoking ban remains constant regardless of whether the other variables are taken into account. The most influential characteristic of all is the presence of an adult non-smoker, which is associated with a fourfold increase in the probability that a household smoking ban will be in place when compared to households in which all the adults are smokers. The presence of a child appears to have little influence on the decision to adopt a household smoking ban. In fact, the impact of this characteristic varies depending on the age of the child: the presence of a child under the age of 6 significantly doubles the probability that smoking restrictions will be in place, while the presence of a pre-adolescent or adolescent child does not appear to have a significant impact. When both a child and an adult non-smoker live in a given household, the chances that a household smoking ban will be in place are seven times greater than in households that do not include one or the other.

\section{Comparisons between Quebec and the other provinces}

Table 4 presents provincial variations in the adjusted effect of each sociodemographic characteristic on the adoption of a household smoking ban. Certain variables were found to have an effect in all four provinces, although the degree of influence varied. Thus, the presence of an adult non-smoker in the household is the characteristic most strongly associated with household 
TABLE 3

Crude and adjusted prevalence ratios (PRs) related to the adoption of a smoking ban (SB) in Quebec households, by sociodemographic variable

\begin{tabular}{|c|c|c|c|c|}
\hline Variables & $\mathbf{n}^{\mathrm{a}}$ & SB $(\% W)^{b}$ & Crude PRs & Adjusted PRs ${ }^{c}$ \\
\hline \multicolumn{5}{|l|}{ Respondent variables } \\
\hline \multicolumn{5}{|l|}{ Age group (in years) } \\
\hline $18-24$ & 156 & 29.5 & $2.4(1.2-5.0)$ & $0.71(0.3-1.8)$ \\
\hline $25-64$ & 718 & 18.1 & $1.3(0.7-2.5)$ & $0.65(0.3-1.4)$ \\
\hline$\geq 65$ & 69 & 13.0 & 1.0 & 1.0 \\
\hline \multicolumn{5}{|l|}{ Gender } \\
\hline Women & 549 & 21.1 & $1.24(0.9-1.7)$ & $1.38(0.9-1.9)$ \\
\hline Men & 400 & 17.7 & 1.0 & 1.0 \\
\hline \multicolumn{5}{|l|}{ Smoking status } \\
\hline Non-smoker & 162 & 29.6 & $2.45(1.6-3.7)$ & $1.09(0.7-1.7)$ \\
\hline Former smoker & 138 & 31.9 & $2.73(1.8-4.1)$ & $1.46(0.9-2.4)$ \\
\hline Current smoker & 649 & 14.6 & 1.0 & 1.0 \\
\hline \multicolumn{5}{|l|}{ Marital status } \\
\hline Living with a spouse & 560 & 19.8 & $1.76(1.0-3.0)$ & $0.82(0.4-1.5)$ \\
\hline Single & 241 & 24.1 & $2.24(1.3-4.0)$ & $1.21(0.6-2.5)$ \\
\hline Separated/divorced & 142 & 11.3 & 1.0 & 1.0 \\
\hline \multicolumn{5}{|l|}{ Education level } \\
\hline Bachelor's degree or higher & 134 & 31.0 & $3.5(2.2-5.5)$ & $3.26(2.0-5.3)$ \\
\hline Postsecondary & 319 & 28.2 & $3.1(2.1-4.5)$ & $2.73(1.8-4.1)$ \\
\hline Secondary or lower & 438 & 11.0 & 1.0 & 1.0 \\
\hline \multicolumn{5}{|l|}{ Perception of ETS as } \\
\hline An important health problem & 566 & 23.3 & $1.8(1.3-2.6)$ & $1.46(1.0-2.1)$ \\
\hline $\begin{array}{l}\text { A health problem of little } \\
\text { or no importance }\end{array}$ & 380 & 14.2 & 1.0 & 1.0 \\
\hline \multicolumn{5}{|l|}{ Household variables } \\
\hline \multicolumn{5}{|c|}{ Presence of $\geq 1$ adult non-smoker } \\
\hline Yes & 576 & 27.6 & $4.70(3.1-7.2)$ & $3.81(2.3-6.4)$ \\
\hline No & 373 & 7.5 & 1.0 & 1.0 \\
\hline \multicolumn{5}{|l|}{ Presence of children } \\
\hline Yes & 449 & 21.8 & $1.29(0.9-1.8)$ & $1.32(0.9-1.9)$ \\
\hline No & 500 & 17.8 & 1.0 & 1.0 \\
\hline \multicolumn{5}{|l|}{ Age of the child (in years) } \\
\hline$\leq 5$ & 155 & 27.7 & $1.79(1.2-2.7)$ & $1.9(1.1-3.1)$ \\
\hline $6-17$ & 293 & 18.8 & $1.08(0.7-1.6)$ & $1.1(0.7-1.6)$ \\
\hline No children & 500 & 20.7 & 1.0 & 1.0 \\
\hline \multicolumn{5}{|l|}{ Effect of family context } \\
\hline Adult non-smoker and child & 283 & 28.6 & $7.1(3.7-13.8)$ & $6.5(3.0-13.9)$ \\
\hline Adult non-smoker, no child & 293 & 26.6 & $6.5(3.3-12.5)$ & $5.6(2.7-11.6)$ \\
\hline Adult smoker and child & 166 & 10.2 & $2.0(0.9-4.5)$ & $2.4(1.0-5.5)$ \\
\hline Adult smoker, no child & & 207 & 5.3 & 1.0 \\
\hline
\end{tabular}

b SB proportions are weighted.

Prevalence ratios have been adjusted for the other variables. smoking bans; this characteristic is associated with an almost fourfold increase in the probability that smoking will be banned in the home in Quebec and Nova Scotia, but only a twofold increase in British Columbia. The second variable associated with the adoption of a household smoking ban is the presence of a child under the age of 6 ; however, the association is weaker and non-significant in Quebec, whereas in Nova Scotia and Ontario it significantly triples the likelihood that a household smoking ban will be in place. The presence of a child over the age of 6 was found to have an effect only in British Columbia, where the presence of children was observed to have a remarkably uniform impact, regardless of age.

Other characteristics were found to have an influence that varies by province. The presence of a child of any age is associated with the adoption of a household smoking ban in Ontario and British Columbia; although non-significant, the strength of this association in Nova Scotia approaches 2 . In British Columbia, the probability that a household smoking ban will be in place is 4 times greater among adults aged 18 to 24 and 25 to 64 than among those aged 65 or over. The influence of a person's smoking status can be observed in Ontario, where former smokers are significantly more likely to adopt a smoking ban than non-smokers and current smokers. The education level of respondents was significantly associated with the adoption of household smoking restrictions in Quebec and Ontario. Neither gender, nor the presence or absence of a spouse appeared to influence the adoption of a smoking ban in any of the provinces included in the study.

\section{Discussion}

The presence of an adult non-smoker in households that include at least one smoker is the factor most often associated with the adoption of a household smoking ban in Quebec and the three other provinces in this study. This confirms the findings of Borland in Victoria, Australia, ${ }^{10}$ who found that smokers in mixed households were 4.7 times more likely to always smoke outside the home than smokers in an allsmoker household (95\% CI 3.7 to 6.0). However, the impact of this variable is less 
TABLE 4

Variations in the effects of sociodemographic characteristics on the adoption of a smoking ban, by province

\begin{tabular}{|c|c|c|c|c|}
\hline Variables & $\begin{array}{c}\text { Quebec } \\
\text { PR }^{\text {a }}(\mathbf{9 5} \% \mathrm{Cl})\end{array}$ & $\begin{array}{c}\text { Ontario } \\
\text { PR }(95 \% \mathrm{Cl})\end{array}$ & $\begin{array}{c}\text { BC } \\
\text { PR }(95 \% \mathrm{Cl})\end{array}$ & $\begin{array}{l}\text { Nova-Scotia } \\
\text { PR }(95 \% \mathrm{CI})\end{array}$ \\
\hline \multicolumn{5}{|l|}{ Respondent variables } \\
\hline \multicolumn{5}{|l|}{ Age group (in years) } \\
\hline $18-24$ & $0.7(0.4-1.2)$ & $1.86(1.09-3.2)$ & $3.6(1.5-8.6)$ & $1.0(0.4-2.4)$ \\
\hline $25-64$ & $0.5(0.3-0.8)$ & $1.42(0.91-2.2)$ & $3.5(1.7-7.2)$ & $1.3(0.3-5.1)$ \\
\hline$\geq 65$ & 1.0 & 1.0 & 1.0 & 1.0 \\
\hline \multicolumn{5}{|l|}{ Gender } \\
\hline Women & $1.3(0.9-1.8)$ & $1.3(1.0-1.6)$ & $1.1(0.7-1.7)$ & $0.8(0.4-1.7)$ \\
\hline Men & 1.0 & 1.0 & 1.0 & 1.0 \\
\hline \multicolumn{5}{|l|}{ Smoking status } \\
\hline Non-smoker & $1.2(0.8-1.8)$ & $1.2(0.8-1.6)$ & $0.5(0.3-0.9)$ & $0.5(0.1-1.5)$ \\
\hline Former smoker & $1.5(0.9-2.3)$ & $1.6(1.1-2.3)$ & $0.5(0.2-0.9)$ & $1.5(0.5-4.8)$ \\
\hline Current smoker & 1.0 & 1.0 & 1.0 & 1.0 \\
\hline \multicolumn{5}{|l|}{ Marital status } \\
\hline Living with a spouse & $0.6(0.4-1.1)$ & $1.0(0.7-1.4)$ & $0.8(0.4-1.4)$ & $0.9(0.3-2.3)$ \\
\hline Single & $1.0(0.5-1.7)$ & $1.0(0.6-1.5)$ & $0.9(0.5-1.8)$ & $0.9(0.3-2.8)$ \\
\hline Separated/divorced & 1.0 & 1.0 & 1.0 & 1.0 \\
\hline \multicolumn{5}{|l|}{ Education level } \\
\hline Bachelor's degree or higher & $2.8(1.7-4.5)$ & $2.4(1.7-3.4)$ & $1.6(0.9-2.9)$ & $1.5(0.5-4.6)$ \\
\hline Postsecondary & $2.4(1.6-3.4)$ & $1.5(1.1-2.0)$ & $2.1(1.2-3.5)$ & $2.2(0.5-5.7)$ \\
\hline Secondary or lower & 1.0 & 1.0 & 1.0 & 1.0 \\
\hline \multicolumn{5}{|l|}{ Perception of ETS as } \\
\hline An important health problem & $1.5(1.0-2.1)$ & $1.3(0.9-1.7)$ & $1.5(0.9-2.5)$ & $1.6(0.6-4.1)$ \\
\hline $\begin{array}{l}\text { A health problem of little } \\
\text { or no importance }\end{array}$ & 1. 0 & 1.0 & 1.0 & 1.0 \\
\hline \multicolumn{5}{|l|}{ Household variables } \\
\hline \multicolumn{5}{|c|}{ Presence of $\geq 1$ adult non-smoker } \\
\hline Yes & $3.8(2.4-5.9)$ & $3.5(2.6-4.7)$ & $2.4(1.5-3.9)$ & $3.7(1.6-8.8)$ \\
\hline No & 1.0 & 1.0 & 1.0 & 1.0 \\
\hline \multicolumn{5}{|l|}{ Presence of children } \\
\hline Yes & $1.2(0.9-1.8)$ & $1.8(1.4-2.3)$ & $2.6(1.6-4.1)$ & $1.9(0.9-4.3)$ \\
\hline No & 1.0 & 1.0 & 1.0 & 1.0 \\
\hline \multicolumn{5}{|l|}{ Age of the child (in years) } \\
\hline$\leq 5$ & $1.6(1.0-2.6)$ & $3.0(2.1-4.2)$ & $2.5(1.4-4.7)$ & $3.5(1.2-10.5)$ \\
\hline $6-17$ & $1.01(0.7-1.5)$ & $1.3(0.9-1.8)$ & $2.7(1.6-4.6)$ & $1.4(0.6-3.5)$ \\
\hline No children & 1.0 & 1.0 & 1.0 & 1.0 \\
\hline \multicolumn{5}{|l|}{ Effect of family pressure } \\
\hline Adult non-smoker and child & $5.7(2.8-11.3)$ & $6.6(4.3-10.2)$ & $6.3(3.1-12.5)$ & $7.9(1.9-32.8)$ \\
\hline Adult non-smoker, no child & $5.3(2.7-10.5)$ & $4.1(2.6-6.3)$ & $2.4(1.2-4.7)$ & $4.1(1.0-16.3)$ \\
\hline Adult smoker and child & $2.0(0.9-4.5)$ & $2.2(1.4-3.5)$ & $2.5(1.2-5.3)$ & $2.2(0.5-9.6)$ \\
\hline Adult smoker, no child & 1.0 & 1.0 & 1.0 & 1.0 \\
\hline
\end{tabular}

a Prevalence ratios have been adjusted for the other variables. pronounced in British Columbia, which suggests that smokers are themselves sufficiently aware of the harmful effects of ETS to adopt a household smoking ban of their own accord, or have a greater willingness to smoke outdoors; British Columbia has a more temperate climate than the other provinces included in this study. From a health promotion standpoint, this suggests a need to consider campaigns that target non-smokers who live with smokers. Unlike classic campaigns that exhort smokers to go outside to smoke, a campaign urging non-smokers to show less tolerance with respect to environmental tobacco smoke might well contribute to a reduction in ETS exposures.

Surprisingly, the presence of children (all ages combined) in smoker households in Quebec is not linked to the adoption of smoking bans, as was found to be the case in British Columbia and Ontario. However, the situation is somewhat improved if the child is under the age of 6 . While the presence of a child appears to have only a weak influence on the adoption of household smoking bans in Quebec, progress has nonetheless been made since 1996, when a Statistics Canada study found that neither the presence of a child, nor the age of the child, had any influence on smoking in the home. ${ }^{7}$ Still, these data are not particularly encouraging in light of the positive impact that household smoking bans have been shown to have on the prevalence of smoking in adolescence. Indeed, a number of authors, including Farkas, ${ }^{11}$ have found that adolescents who live in smoke-free households were only $74 \%$ as likely to be smokers as adolescents who live in households where there are no smoking restrictions. Farkas also observed that adolescents who already smoke are twice as likely to stop smoking if they live in a smoke-free household. Wakefield ${ }^{12}$ has observed that transition through the different stages of tobacco addiction was significantly slower for adolescents who reported that their household had a smoking ban. The results of our study have important operational implications for public health programs, since they suggest parents are more inclined to adopt a smoking ban when their children are young but become less inclined to do so 
as their children age. In addition to the link between child health and household smoking bans, greater emphasis should be placed on the impact of smoking bans on children's future smoking behaviour.

The perception of ETS as an important health issue also has an impact that falls within the range of statistical significance. The proportion of respondents who viewed ETS as a health problem of little or no importance was substantial in 2001 (40\%). Although that proportion has probably declined since the data were collected, it remains a variable of considerable interest from a public health perspective by virtue of the fact that it is modifiable.

Contrary to the findings of some authors, the adoption of household smoking bans was not linked to the gender of respondents in Quebec or in the three other provinces in this study. These results differ from those of Gilpin ${ }^{13}$ and Merom ${ }^{14}$ who found that women adopt such household policies significantly less often than men, with odds ratios of $0.72 \mathrm{CI}(0.61$ to 0.84$)$ and $0.84 \mathrm{CI}$ (0.72 to 0.96 ) respectively. As far as the age of respondents is concerned, we observed that this characteristic had no influence on the adoption of smoking bans in Quebec households. This is surprising, given that participants aged 18 to 24 belong to a generation whose members are better informed about the harmful effects of ETS and are more likely to have small children at home.

The strength of this study resides in the potential to identify the factors which are associated with the presence of a smoking ban in "smoker households" in Quebec. In public health, it is crucial to be able to identify factors that can explain at least part of a problem that affects the population and are viewed as modifiable. The results of this study suggest that ETS in the home is at least partly modifiable if a less tolerant, non-smoking adult lives with a smoker and if the perception of ETS as an important health problem increases. The results also suggest that parents are less likely to perceive the benefits of a household smoking ban when their children are 6 or older. These hypotheses, once confirmed, will serve as a basis for modifying health promotion interventions. In fact, a Chinese study ${ }^{15}$ on the predictive factors of lax household smoking bans points to the presence of a smoking partner (odds ratio $=2.78$, $p<0.05)$.

One might argue that these data are too old, since they date back to 2001 . However, the results of this study remain fully relevant for a number of reasons. To begin with, the study constitutes the only epidemiological index currently at our disposal, as it is the first study of its kind to include a representative sample of the Canadian population; also, as far we know, no other study has ever been published on the factors associated with the adoption of household smoking bans in Quebec. As such, the results of this study will ultimately lend themselves to comparisons with future studies. Finally, the results of the 2006 Canadian Tobacco Use Monitoring Survey (CTUMS) show that these data are still relevant, since Quebec remains above the Canadian average in terms of household second-hand smoke exposure for children aged 0 to 17; in Quebec, $18.4 \%$ of children aged 0 to 11 and $25.8 \%$ of children aged 11 to 17 are regularly exposed to ETS, compared to $3 \%$ and $7 \%$ respectively in British Columbia, $5 \%$ and $8.9 \%$ in Ontario, and $10.5 \%$ and $18 \%$ in Nova Scotia. ${ }^{8}$

Quebec's Tobacco Act, which prohibits smoking in many places (health care facilities, daycare centres, social services, schools and institutions of higher learning, sports and recreational facilities, arts and cultural facilities, public transit) has been in place since 2001. On May 31, 2006, smoking was prohibited in bars and restaurants as well. This new measure, combined with the Tobacco Act, will no doubt have an impact on the social acceptability of smoking, but its effect on household smoking bans is unlikely to be so great as to invalidate the results of the present study.

This study comprises a few limitations that should be noted. The response rate of $62 \%$ is modest and, as such, may cast doubt on the reliability of household smoking ban data. However, it is well within the range of response rates routinely obtained with the method used. Indeed, survey response rates have been trending downward in recent years, compared to the 1970s, 1980s and 1990s. ${ }^{15,16}$

Moreover, dividing the household smoking ban variable into two categories (complete household smoking ban and occasional/ no ban) tends to group into the latter category both households that have never had a ban and households in which a ban exists but is occasionally disregarded. Although having three categories might have provided a more accurate reflection of reality, our interest lies in households that have a complete smoking ban, since our goal is to identify the variables associated with such bans; furthermore, the small size of certain sub-groups limited our options in this regard.

As for the weighting of prevalence estimates in this study, the coefficients should have been calculated on the basis of the distribution of households as reflected in national statistics. In the absence of such statistics, these coefficients were obtained on the basis of the distribution of households participating in the survey, which constitutes a reliable estimate of national data. Consequently, the estimated prevalences in our study are probably close to the real numbers.

Finally, the results for Nova Scotia should be interpreted with prudence, given the small sample size $(n=132)$. This factor makes it difficult to distinguish between an absence of association and the study's inability to detect an association where one exists.

\section{Conclusion}

The performance of Quebec's tobacco control strategy, the diminishing social acceptability of smoking, and legislation that prohibits smoking in public places and workplaces have brought about a reduction in smoking prevalence. However, Quebec's children do not all enjoy the benefits of these changes and remain more exposed to ETS than children in other parts of Canada. The results of this study provide a more accurate profile of children's exposure 
to ETS in the home. They suggest that children who live in smoker households that do not include any adult non-smokers are at greater risk of exposure to ETS than those who live with at least one adult nonsmoker. These findings also suggest that the adoption of a smoking ban is viewed as acceptable for younger children but less so for older children, which could have important operational implications for public health programs. The strong association between the presence of adult non-smokers and the adoption of household smoking bans also raises health promotion implications and suggests that intervention campaigns aimed at non-smokers who live with smokers should incite the former to be less tolerant of environmental tobacco smoke in the home.

\section{References}

1. Centre National de Documentation sur le Tabac et la Santé. Faits saillants - la fumée de tabac dans l'environnement : ses conséquences générales pour la santé. Ottawa ON: Canadian Council for Tobacco Control; 1996 Mar.

2. Glantz SA, Parmley WW. Passive smoking and heart disease. Mechanisms and risk. JAMA. 1995 Apr 5;273(13):1047-53.

3. Sandler DP, Wilcox AJ, Everson RB. Cumulative effects of lifetime passive smoking on cancer risk. Lancet. 1985 Feb 9; 1(8424):312-5.

4. Pizacani BA, Martin DP, Stark MJ, et al. Household smoking bans: which households have them and do they work? Prev Med. 2003;Jan;36(1):99-107.

5. Ashley MJ, Cohen J, Ferrence R, et al. Smoking in the home: changing attitudes and current practices. Am J Public Health. 1998 May;88(5):797-800.

6. EKOS Research Associates Inc. An assessment of knowledge, attitudes and practices concerning environmental tobacco smoke. Final report. Ottawa, Ontario. 1995 Mar 31. Submitted to Health Canada.
7. Ashley MJ, Ferrence R. Environmental tobacco smoke (ETS) in home environments: a discussion paper prepared for Health Canada's Strategic Planning Workshop to Reduce ETS. Ottawa, Ontario: The Ontario Tobacco Research Unit; 1995 October 19-20.

8. Health Canada. Canadian tobacco use monitoring survey (CTUMS): section on households. Ottawa (ON): Health Canada; 2006. Available from: http://www.hc-sc.gc.ca/ hl-vs/tobac-tabac/research-recherche/stat/ _ctums-esutc_2006/ann-table9-eng.php

9. Northrup DA. Environmental tobacco smoke in the home: a national survey technical documentation. Toronto: Institute for Social Research, York University; 2002.

10. Borland R, Mullins R, Trotter L, et al. Trends in environmental tobacco smoke restrictions in the home in Victoria, Australia. Tob Control. 1999;8(3):266-71.

11. Farkas AJ, Gilpin EA, White MM, et al. Association between household and workplace smoking restrictions and adolescent smoking. JAMA. 2000;284(6):717-22.

12. Wakefield MA, Chaloupka FJ, Kaufman NJ, et al. Effect of restrictions on smoking at home, at school, and in public places on teenage smoking: cross sectional study. BMJ. 2000;321(7257):333-7.

13. Gilpin EA, White MM, Farkas AJ, et al. Home smoking restrictions: which smokers have them and how they are associated with smoking behavior. Nicotine Tob Res. 1999;1(2):153-62.

14. Merom D, Rissel C. Factors associated with smoke-free homes in NSW: results from the 1998 NSW Health Survey. Aust N Z J Public Health. 2001;25(4):339-45.

15. Mak YW, Loke AY, Abdullah AS, Lam TH. Household smoking practices of parents with young children, and predictors of poor household smoking practices. Public Health. 2008 Nov;122(11):1199-209. Epub 2008 Jul 10.
16. Dunkelberg WC, Day GS. Non response bias and call backs in sample surveys. J Mark Res. 1973;10:160-8.

17. Dillman DA. Mail and internet surveys: the tailored design method. New York: John Wiley \& Sons; 2000. 464 p. 